\title{
Regulatory Application Sponsor Effective Date Range
}

National Cancer Institute

\section{Source}

National Cancer Institute. Regulatory Application Sponsor Effective Date Range. NCI

Thesaurus. Code C94048.

The date and time span for when the regulatory application sponsor is active. 